\title{
Desarrollo ideológico-cultural y apropiación del discurso académico entre estudiantes universitarios
}

\author{
Desenvolvimento ideológico-cultural \\ e apropriação do discurso acadêmico \\ entre estudantes universitários
}

Gregorio Hernández Zamora*

*Universidad Autónoma Metropolitana - UAM, Ciudad de México / México grehz@yahoo.com

\begin{abstract}
RESUMEN: La escritura académica se ha visto principalmente como un proceso cognitivo y lingüístico. Este artículo explora la dimensión ideológicocultural en el desarrollo del proceso escritor de estudiantes universitarios de bajo estatus socioeconómico en México, a partir de producciones textuales diseñadas para conectar ideas previas y conocimiento académico. El análisis preliminar muestra que una mayor madurez en la escritura (corrección, claridad, argumentación, pensamiento crítico) tiende a estar conectada con una relación más informada, reflexiva, distante y crítica con las ideologías e identidades culturales disponibles en el medio social; mientras que una escritura más problemática (en forma y contenido) suele asociarse con una relación más inmediata, reproductiva y acrítica con las ideologías e identidades culturales adquiridas desde la infancia. Concluimos tentativamente que la identidad ideológico-cultural plantea, con frecuencia, un conflicto en la apropiación de la cultura escrita universitaria.
\end{abstract}

PALABRAS CLAVE: literacidad académica; identidad cultural; desarrollo ideológico; escritura académica; educación superior; México.

RESUMO: A escrita acadêmica tem sido vista principalmente como um processo cognitivo e linguístico. Este artigo explora a dimensão ideológica e cultural escritor desenvolvimento da escrita de estudantes universitários de baixo nível socioeconômico no México, a partir de produções textuais projetados para se conectar ideias anteriores e conhecimento acadêmico. A análise preliminar mostra que uma maior maturidade, por escrito (correção, clareza, argumentação, o pensamento crítico) tende a ser conectado com um relacionamento mais informada, pensativo, distante e crítico com as ideologias e identidades culturais disponíveis no ambiente social; Considerando que uma escrita mais problemática (em forma e conteúdo) geralmente está associada a uma relação mais imediata, reprodutiva e acrítica com as ideologias e identidades 
culturais adquiridas desde a infância. Achamos tentativamente que a identidade ideológico-cultural muitas vezes levanta um conflito na apropriação da cultura escrita da universidade.

PALAVRAS-CHAVE: alfabetização acadêmica; identidade cultural; desenvolvimento ideológico; escrita acadêmica; ensino superior; México.

\section{Introducción}

\subsection{Teorías de la apropiación del discurso académico}

La investigación sobre la apropiación del discurso académico se ha enfocado desde tres grandes perspectivas: una perspectiva cognitiva, una perspectiva lingüística, y una perspectiva sociocultural. Desde la visión cognitiva se han visto las dificultades de los estudiantes con la escritura en general, y con la escritura académica en particular, como un problema de habilidades y estrategias generales (composición, argumentación etc.), o bien particulares (planeación, revisión, corrección etc.). Los estudios pioneros de Hayes y Flower (1980), por ejemplo, se basaron en el método del protocolo de pensamiento en voz alta (thinking aloud protocol), que consiste en pedir a los escritores que digan lo piensan mientras escriben. Así, Hayes y Flower llegaron a la distinción entre escritores competentes y novatos, según la cual el problema de los novatos es su falta de estrategias de escritura, y su enfoque en el contenido local del texto en detrimento del contenido global. Los trabajos de estos autores dieron pie a la pedagogía del llamado proceso de escritura (planeación-escritura-revisión-reescritura). Esta perspectiva de la escritura como proceso cognitivo (observable en estrategias y habilidades) ha sido cuestionada y en gran medida abandonada en los países donde se originó (HULL; HERNANDEZ-ZAMORA, 2008). Sin embargo, en varios países de Latinoamérica aún se usa y en algunos apenas se empieza a introducir, tanto en propuestas pedagógicas como en la investigación (por ejemplo, ERRAZURIZ et al., 2015).

Por otro lado, desde una perspectiva, en buena parte lingüística, autores como Goody y Watt (1968), Olson (1977) y Ong (1982) plantearon que la oralidad y la escritura eran dos modos discursivos esencialmente distintos y opuestos. Así, las dificultades con la escritura se explicarían por su naturaleza "descontextualizada" (distancia espacio-temporal entre interlocutores) y por los patrones sintácticos "más complejos" del 
texto escrito, en comparación con la sintaxis "simple" del enunciado oral (OLSON, 1977). Al igual que la visión cognitiva, esta perspectiva ha decaído en sus países de origen, debido a la profusa investigación etnográfica y sociocultural que echó por tierra varios de sus supuestos clave, como la dicotomía oralidad-escritura, la supuesta mayor complejidad del lenguaje escrito, o la supuesta descontextualización de la escritura. No obstante, al igual que la perspectiva cognitivista, la perspectiva fuertemente lingüística aun predomina en ciertos círculos académicos y educativos en América Latina, donde se dedican muchos recursos a investigar, evaluar y diagnosticar todas y cada una de las minucias gramaticales, ortográficas y estilísticas en la escritura de estudiantes que, por regla general, resultan muy deficientes en este tipo de evaluaciones. Ejemplos de este tipo de estudios y perspectivas abundan. En México, por ejemplo, la Asociación Nacional de Universidades e Instituciones de Educación Superior ha patrocinado estudios de este tipo, como el reportado por González (2015) bajo el título Habilidades lingüísticas de los estudiantes de primer ingreso a las instituciones de educación superior del área metropolitana de la ciudad de México, que tuvo por objetivo

medir el grado en que el estudiante maneja habilidades lingüísticas que le permiten integrar nuevos conocimientos [...] [así como el grado en que] analiza y aplica conceptos básicos de gramática y de uso normativo que permiten desarrollar la conciencia lingüística indispensable para producir textos adecuados al ámbito académico (GONZÁLEZ, 2015, p. 124).

Una consecuencia negativa, a mi juicio, de esta perspectiva es que al constatar los mil y un errores gramaticales, ortográficos y textuales que los estudiantes cometen al escribir, vuelven a caer en la antigua tentación de recomendar reformas curriculares centradas en la enseñanza de conocimiento metalingüístico (lenguaje para hablar sobre la lengua), tal y como lo expresa Munguía (2015), una de las coautoras del estudio de ANUIES en su listado final de recomendaciones, donde propone incluir, en los programas reformados contenidos como estos: fonética, fonología, morfología, sintaxis, semántica, gramática textual, además de contenidos vinculados a otras ramas de la lingüística, como la psicolingüística, la sociolingüística, la pragmática y el análisis literario. Otro ejemplo de estudios recientes en esta línea es la medición de los "niveles de literacidad" que un grupo de investigadores (HENAO et al., 2011) realizaron con estudiantes universitarios en Colombia. Aunque este estudio incluía un 
componente de lectura crítica, gran parte del instrumento se diseñó para medir aspectos lingüístico-textuales, tales como ortografía, puntuación, cohesión, coherencia, adecuación, marcadores y conectores, entre otros.

Sin negar que las perspectivas cognitiva y lingüística han aportado a nuestro conocimiento sobre los problemas y dificultades de nuestros estudiantes en la apropiación del discurso académico, ambas presentan limitaciones clave que discuto en el resto del artículo. Una de ellas, especialmente notable, es la conceptualización que hacen del sujeto como un sujeto psicológico, y de la actividad de escribir como una habilidad cognitiva. Frente a esta visión, a menudo denominada "mentalista" desde los años 80 del siglo $\mathrm{XX}$, surge una fuerte corriente de estudios etnográficos y socioculturales que caracterizan el lenguaje hablado y escrito como una práctica social-discursiva inseparable de los contextos sociales, culturales e históricos en donde tiene lugar, y el aprendizaje como un proceso socialmente situado y mediado por conflictos no solo cognitivos, sino también de identidad ideológico-cultural, derivados de las relaciones asimétricas de poder, de identidad y de legitimidad que caracterizan a la sociedad actual. En estos estudios, se conceptualizan las formas hablada y escrita de la lengua como parte de un continuo oralidadescritura-actividad, más que como polos opuestos, especialmente cuando se le observa en contextos y prácticas sociales reales. Esta corriente se nutre por un lado de los estudios socioculturales del aprendizaje (BRUNER, 1986; LAVE; WENGER, 1991; VYGOTSKY, 1978), y por otro de los llamados nuevos estudios de literacidad (BARTON, 1994; BARTON; HAMILTON; IVANIC, 2000; GEE, 1991, 1996; HEATH, 1983; SCRIBNER; COLE, 1981; STREET, 1984). Desde este punto de vista, y a través de múltiples estudios etnográficos del lenguaje en uso, se planteó que los estudiantes que provienen de grupos no dominantes, no solo deben aprender las "convenciones" de la escritura y el discurso académicos, sino que deben apropiarse del lenguaje del otro, lo que involucra conflictos de identidad y autenticidad cultural, lingüística e ideológica (BARTHOLOMAE, 1985; CANAGARAJAH, 2002; GEE, 2004; IVANIC, 1998; ROSE; HULL, 1989). Estos conflictos surgen porque el lenguaje y sus prácticas de uso no son inventados por los individuos, sino que éstos lo adquieren al pertenecer y participar en comunidades lingüísticas y discursivas que, a su vez, producen y reproducen prácticas sociales más amplias, tales como prácticas políticas, económicas, educativas, religiosas, deportivas, laborales, jurídicas etc. El acceso a estas prácticas plantea ya dificultades socioeconómicas, además de 
conflictos y dilemas de identidad cultural, y no solo dificultades cognitivas o psicolingüísticas. Entrar en una comunidad discursiva de tipo académico no es, por lo tanto, solo un asunto de "habilidades y competencias académicas", sino también un asunto de poder, acceso, legitimidad e identidad (HERNÁNDEZ-ZAMORA, 2009, 2017).

\subsection{El aula y la lengua como espacios de tensiones ideológicas}

Desde esta última perspectiva, el aula es vista no solo como un espacio pedagógico de relaciones de enseñanza-aprendizaje, sino también como un espacio atravesado por relaciones y tensiones políticas, ideológicas y culturales; y el aprendizaje no es visto solo como un proceso de evolución y conflicto cognitivo, sino también como un proceso conflictivo de relaciones asimétricas de poder (entre alumnos y académicos, y las clases sociales que representan), y de ideologías en competencia (IVANIC, 1998). Por lo tanto, apropiarse del discurso académico implica hablar la lengua del otro dominante (los académicos, las clases medias educadas, los grupos étnicos dominantes etc.). Esto conlleva dilemas de lealtad cultural e ideológica entre, por ejemplo, el ateísmo científico y la religiosidad popular; entre el liberalismo (o radicalismo) político de los profesores y el conservadurismo de las familias de origen de los alumnos; entre el elitismo y el esteticismo cultural del mundo educado y el pragmatismo prosaico de la cultura de masas de los barrios de origen de nuestros estudiantes; entre el lenguaje "correcto" y a menudo pedante de las clases medias educadas (representadas por los profesores) y el lenguaje "incorrecto" y "vulgar" de las clases trabajadoras (representadas por los alumnos); entre el individualismo de la escritura ensayística y el colectivismo de la oralidad popular; entre el escepticismo y el constructivismo epistemológicos de la academia y la credulidad y el realismo ingenuo del mundo popular.

\subsection{Consecuencias en la escritura}

Ciertamente se producen conflictos cognitivos en la universidad que son productivos para el aprendizaje, pero con frecuencia se producen también conflictos ideológico-culturales que más bien impiden el diálogo auténtico y obstruyen el aprendizaje. Cuando estos conflictos pasan desapercibidos para los docentes, o estos intencionalmente los evaden para evitar "conflictos y discusiones", o bien por "respeto a la diversidad 
de creencias", lo que se hace es impedir que las ideologías subyacentes se incorporen como objetos legítimos de estudio y discusión en clase, y esto contradice las intenciones declaradas de formar alumnos con pensamiento crítico y valores democráticos.

¿Qué relación tiene esta problemática con la apropiación del discurso académico, especialmente a través de la escritura? Un problema notable es que al caracterizar y/o evaluar la escritura de los estudiantes desde perspectivas puramente psicológicas o lingüísticas, se suele tratar el lenguaje solo como forma y no como contenido; y al acto de escribir como habilidad psicológica y no como acción social. Desde esta mirada, la intervención pedagógica se enfoca en desarrollar la competencia discursiva, pero no la conciencia y la agencia de sujeto. Es decir, es una visión instrumental del lenguaje, que lo ve solo como "herramienta comunicativa", versus una visión constitutiva del lenguaje, que lo ve en sí mismo como posibilidad de emergencia y devenir del sujeto como persona y como actor social (BAKHTIN, 1981; FREEDMAN y BALL, 2004; GEERTZ, 1992; HERNÁNDEZ-ZAMORA, 2017; CAMARGO, 2017).

Sabemos bien, sin embargo, que uno de los aspectos más problemáticos de la escritura de los estudiantes es el contenido de lo que escriben, especialmente en aspectos tales como:

- Insuficiencia: esbozo de ideas con escaso o nulo desarrollo.

- Irrelevancia: ideas inconexas o tangenciales al tópico central del texto.

- Pensamiento acrítico: Ideas que no cuestionan, sino que asumen acríticamente y, por tanto, reproducen las ideologías y los discursos dominantes sobre las relaciones de clase, género, etnicidad, religión, estatus, edad etc.

Es este último aspecto (pensamiento acrítico) el que ha sido poco tratado en la literatura vinculada al desarrollo escritor y, por tanto, a la literacidad académica en su faceta de contenido de lo que se escribe o se dice.

\subsection{Perspectiva Bakhtiniana sobre la apropiación del lenguaje}

De manera consistente con los enfoques socioculturales del aprendizaje y de la lengua, el lingüista y teórico literario Mikhail Bakhtin (1981) teorizó el lenguaje como un performance atravesado por múltiples 
voces que expresan puntos de vista o lenguajes sociales. Acuñó el término heteroglosia para referir este carácter multi-vocal de todo acto de habla o de escritura, idea que Cazden capturó en forma elocuente en esta cita:

Los escritos de Bakhtin llaman la atención sobre situaciones de habla o de escritura particulares, sobre las complejidades de encontrar una voz, de ser comunicativamente competente, en situaciones sociales heteroglósicas, donde las voces (y los roles que estas expresan en la estructura social) son sentidas por el hablante o el escritor como voces en conflicto (CAZDEN 1992, mi traducción).

El concepto de heteroglosia implica entonces que para hablar o escribir, el sujeto debe elegir palabras-ideas que nunca son neutrales, sino que representan voces divergentes o incluso antagónicas en la sociedad. Bakhtin introdujo el término desarrollo ideológico para referirse al proceso de encontrar una voz propia, es decir un lugar social desde donde hablar. Visto así, la apropiación del discurso académico tiene más que ver con el posicionamiento del escritor en relación con los marcos ideológicos desde donde piensa y habla, que con el conocimiento de las convenciones formales del texto. Esto es fundamental, pues el lenguaje si bien tiene forma (forma fonética, sintáctica, léxico-estilística, genérico-textual etc.) es, ante todo, un medio para la construcción y expresión de la subjetividad individual.

\subsection{Devenir ideológico y desarrollo letrado}

El mundo es un lugar no solo para ser descrito y conocido, como lo piensa el sentido común de muchos estudiantes; sino que es el lugar donde existimos y actuamos, y donde encontrar un lugar propio exige implicarse con uno mismo y respecto a los otros. El mundo actual es, además, un lugar marcado por divisiones sociales extremas, como nos lo recuerdan Ball y Freedman (2004) en el capítulo introductorio del volumen Bakbtinian perspectives on language, literacy, and learning. Señalan las autoras que se trata de divisiones y antagonismos ideológicos y culturales, producto de una polarización social que nos separa en clases, razas, naciones, géneros, grupos étnicos, religiones y otras fronteras sociales. Es imposible pensar, hablar y escribir dentro de este contexto social sin hacerlo desde cierta posición y postura. No obstante, los hablantes/escritores no siempre tienen consciencia del poder de la estructura social para posicionarlos en sus roles e identidades, ni tampoco de su propia capacidad para auto-posicionarse. La lengua en 
general, y la escritura académica en particular, pueden ser un dispositivo de agencia que permita a los sujetos desarrollar un mínimo de poder para resistir el ejercicio de un poder que impone un deber ser (ESPINOZA, 2016).

Es en este mundo de divisiones sociales extremas entre quienes tienen y quienes no tienen, entre quienes definen su identidad y quienes son definidos por corporaciones que manufacturan identidades, entre quienes tienen acceso a diversas perspectivas y quienes viven confinados en un solo punto de vista etc., donde muchos estudiantes parecieran no encontrar un lugar para sí mismos, es decir una voz para hablar desde y a través de las diferencias, de manera que se limitan a reproducir y recitar los discursos ajenos, en especial los discursos fabricados por agentes con poder económico, político, cultural o espiritual. Freedman y Ball sostienen que es necesario investigar cómo puede comunicarse la gente a través de estas divisiones sociales y qué rol puede jugar este tipo de comunicación en la enseñanza-aprendizaje (FREEDMAN; BALL, 2004).

Para ello, estas autoras recuperan y desarrollan el concepto de devenir ideológico (ideological becoming) acuñado por Bakhtin para referirse al desarrollo de nuestra visión del mundo, o sea, nuestros sistemas de ideas o ideologías. Desde un punto de vista evolutivo, todo proceso de desarrollo involucra siempre un qué y un cómo. En este caso, el qué es lo que Bakhtin llama el ser ideológico, que yo prefiero denominar sujeto ideológico, análogo, pero diferente al sujeto cognitivo de las teorías evolutivas del aprendizaje, o al sujeto social, de las teorías sociales. Estos conceptos apuntan a distinguir dimensiones distintas del desarrollo del sujeto entero en el mundo (LAVE; WENGER, 1991). Lo interesante del concepto de sujeto ideológico, en relación con el desarrollo del sujeto discursivo (hablante, escritor, letrado) es que apunta justo a la dimensión contenido o semántica del lenguaje, a diferencia de la noción de sujeto lingüistico o sujeto alfabetizado o sujeto lector/ escritor, que suelen apuntar a la dimensión formal o sintáctica del lenguaje.

Ahora bien, de acuerdo con Bakhtin, "nuestro desarrollo ideológico es [...] una intensa lucha interna por la hegemonía entre varios puntos de vista ideológicos y verbales, enfoques y valores disponibles" (1981, p. 341). El desarrollo o devenir ideológico de un ser humano es, según Bakhtin, "el proceso de asimilación selectiva de las palabras de otros" (1981, p. 341). En el proceso de desarrollo o apropiación o asimilación de palabras ajenas, el rol del otro es crítico. Entre más opciones de palabras para asimilar tengamos, mayores oportunidades tendremos de aprender, señalan Freedman y Ball 
(2004). Sin embargo, Bakhtin teoriza que "nuestro desarrollo ideológico es tal lucha intensa dentro de nosotros mismos por la hegemonía entre varios puntos de vista, enfoques y valores ideológicos y verbales disponibles" (1981, p. 346).

Freedman y Ball derivan de lo anterior una consecuencia pedagógica: toda práctica de enseñanza-aprendizaje y todo proceso de apropiación del lenguaje implican decisiones políticas:

los estudiantes deciden qué tanto identificarse y adquirir el lenguaje y las maneras académicas; llegan a la escuela con maneras de hablar que los marcan como miembros de clases socioeconómicas particulares, y ellos deciden si se alejan o no de esas formas; deciden qué leer y escribir y si les importa más complacer al maestro, a sus pares, a ambos, o a ninguno. Todas estas son decisiones políticas, en términos generales. De igual forma, los maestros deciden cómo responder a los patrones lingüísticos diversos en las aulas; qué tanta controversia introducir en las clases; cómo agrupar o no agrupar a los alumnos para el aprendizaje; cómo responder a los individuos y al grupo; o si enseñarán críticamente, en formas que empujen a los alumnos a examinar el orden social establecido. De nuevo, estas son también decisiones políticas (BALL; FREEDMAN, 2004, p. 5, mi traducción).

\subsection{Discurso autoritativo vs internamente persuasivo}

Bakhtin sostiene que cuando diversas voces interactúan, luchamos por asimilar dos categorías distintas de discurso: a) el discurso autoritativo y, b) el discurso internamente persuasivo. Bakhtin define discurso autoritativo como

la palabra autoritaria, por así decir, la palabra de los padres; su autoridad ya fue reconocida en el pasado. Es un discurso a priori, por tanto no está sujeto a elección entre otras opciones posibles, pero iguales. Se da y se escucha en las altas esferas, no en el contacto familiar, por ejemplo es la autoridad del dogma religioso, o la verdad científica reconocida, o un libro de moda. La palabra autoritaria exige que la reconozcamos, que la hagamos nuestra; nos envuelve, independientemente de si tiene poder o no de persuadirnos internamente; nos topamos con ella investida ya de una autoridad (BAKHTIN, 1981, p. 342-343, mi traducción).

Por su parte, el discurso internamente persuasivo carece de todo privilegio, "no tiene respaldo de ninguna autoridad, y con frecuencia no tiene siquiera reconocimiento social" (BAKHTIN, 1981, p. 342). Es lo que cada 
persona piensa por sí misma, lo que ultimadamente la persuade. Conforme formamos nuestras ideas, entramos en contacto con los discursos de otros y estos discursos entran en nuestra conciencia tanto como los discursos autoritativos. De hecho, "una variedad de discursos ajenos entran a una lucha por influir en la consciencia de un individuo, justo como luchan entre sí en la realidad social circundante" (1981, p. 348).

\section{Métodos}

Los participantes en este estudio son estudiantes de una universidad pública con cinco campus en la zona metropolitana de la Ciudad de México. Gran parte de los estudiantes de esta universidad habita en zonas marginadas de la periferia urbana, pertenecen a familias de clase trabajadora de nivel socioeconómico bajo y de escolaridad muy limitada. Los alumnos provienen en su mayoría de escuelas públicas con carencias notables en cuanto a los ambientes y experiencias de aprendizaje que ofrecen, por lo que ingresan a la universidad con serias limitaciones en sus conocimientos generales y en su destreza y eficacia en el manejo del lenguaje oral y escrito. La universidad donde se realiza el estudio ha planteado medidas tanto de tipo diagnóstico como de intervención (examen de admisión general; examen de español como lengua escrita, cursos remediales, cambios curriculares etc.); sin embargo, estas acciones se enfocan en atender aspectos de gramática oracional y textual, que justo pierden de vista la naturaleza del lenguaje como una unidad sintáctico-semántica, en donde están en juego no solo formas gramaticales o textuales, sino también ideologías y discursos.

Los datos presentados en este artículo se basan en el análisis parcial de un corpus amplio de producciones escritas, realizadas entre 2011 y 2017 por más de 800 estudiantes del área de ciencias sociales y humanidades de la Universidad Autónoma Metropolitana (Ciudad de México). El corpus extenso es parte del proyecto (actualmente en etapa avanzada) titulado Nexos lenguaje-cultura-cognición en la formación de sujetos letrados, que es simultáneamente un proyecto de intervención e investigación. Se basa en el diseño y en la conducción de actividades didácticas cuya finalidad es que los alumnos expresen ideas propias, relacionen conocimientos y experiencias previos con los contenidos académicos, y pongan en juego sus identidades personales y culturales al abordar contenidos académicos. Estas actividades se han realizado con alrededor de 30 grupos en los siguientes cursos de licenciatura 
impartidos por el investigador: Taller de Escritura para Universitarios, Taller de Lenguaje y Argumentación, Taller de Interpretación y Argumentación, Taller de Literacidad Académica, Cultura Contemporánea, Seminario de Integración, Seminario Terminal, y Proyecto Terminal. El corpus de textos será analizado desde tres dimensiones: lingüística, textual y discursiva.

Este artículo reporta parte del análisis de la dimensión discursiva, la cual se enfoca en las ideologías e identidades culturales que se traslucen a través de la escritura de los alumnos. Para ello, se eligieron los casos de cinco estudiantes (Tabla 1), a partir de un análisis ideológico-discursivo (posicionamiento del escritor ante los discursos dominantes y, por tanto, frente al tema de su escrito) del cual se construyeron cuatro categorías analíticas: Distancia 0 (el sujeto no se distingue a sí mismo del discurso que enuncia), Distancia 1 (el sujeto intenta usar conceptos con fines analíticos, pero su ejercicio es incipiente), Distancia 2 (el sujeto comienza a usar algunos conceptos con fines analíticos y críticos), Distancia 3 (el sujeto toma distancia de los discursos hegemónicos y los somete a escrutinio y/o crítica con base en conceptos, teorías, autores o datos). Para explicar la idea de "distancia" se hace una analogía con la película Matrix (ver explicación extensa después de la exposición de resultados).

TABLA 1 - Informantes seleccionados para este reporte

\begin{tabular}{|l|l|l|l|}
\hline Alumno/a* & \multicolumn{1}{|c|}{ Curso } & \multicolumn{1}{c|}{ Texto } & \multicolumn{1}{c|}{ Ideología / Caso } \\
\hline Beatriz & Taller de literacidad académica & Artículo IMRD & Dentro de la Matrix \\
\hline Ernesto & Cultura contemporánea & Ensayo autobiográfico & Dentro de la Matrix \\
\hline Graciela & Cultura contemporánea & Ensayo autobiográfico & Dentro de la Matrix \\
\hline Keyla & Cultura contemporánea & Ensayo autobiográfico & Saliendo de la Matrix \\
\hline Lisset & Taller de lenguaje y argumentación & Ensayo argumentativo & Fuera de la Matrix \\
\hline
\end{tabular}

* Todos los nombres son pseudónimos

\section{Resultados}




\subsection{Caso 1: Ideología de género (dentro de la Matrix)}

En el contexto del curso Taller de literacidad académica, se pidió a los alumnos realizar una pequeña investigación cuantitativa y cualitativa, sobre un tema de su elección, y que se reportara en formato de artículo IMRD (Introducción, Métodos, Resultados, Discusión).

Beatriz ${ }^{1}$ (pseudónimo) escribió su artículo IMRD sobre el tema "Arreglo y dedicación al arreglo personal que llevan las Universitarias de la Autónoma Metropolitana". Su texto aborda un tema ampliamente debatido tanto en los estudios sociales como en la sociedad actual: el sexismo y la identidad de género. Beatriz, sin embargo, mantiene una postura que podríamos llamar "tradicionalista" o conservadora sobre el tema. Según el texto de Beatriz, es muy importante que las mujeres cuiden su arreglo personal y, en particular, que recurran al maquillaje con el fin de lograr "auto-aceptación” y "proyectar seguridad". El texto tiene 5 páginas, a espacio cerrado, e incluye gráficas y resultados de la encuesta que Beatriz realizó entre alumnas de la universidad, así como sus apreciaciones e interpretaciones. Así lo expresa al inicio del artículo:

Este artículo presenta la investigación realizada con alumnos de la licenciatura de la UAM Cuajimalpa. El objetivo fue conocer las necesidades cosméticas entre las alumnas de la Universidad explícitamente en el aspecto de la belleza, los estándares y la auto-aceptación

Es notable la forma en que Beatriz se posiciona con respecto al tema de estudio. Al introducir la categoría "necesidades cosméticas", plantea ya una visión sobre las diferencias de género que, desde su punto de vista, aparecen como naturales. A lo largo de su escrito, Beatriz mantiene esta postura que naturaliza el "arreglo personal" como "nuestra primera carta de presentación":

Se encontró que la mayoría de las estudiantes recurren a diario al maquillaje, esta de mas mencionar que a primera hora los baños de la UAMC explícitamente el de las Damas está lleno y no es por que deseen evacuar el desayuno que seguramente hicieron a prisa, mas bien, para retocarse el maquillaje que venían haciéndose en el transporte, No es algo

\footnotetext{
1 Todos los nombres son pseudónimos y todos los textos escritos por alumnos se transcriben tal cual los escribieron ellos, es decir con su ortografía y sintaxis original.
} 
que sea malo pues nuestra higiene y arreglo personal es nuestra primera carta de presentación y no es que si seas bonita o fea (que a mi forma de pensar no existe mujer fea, si no mujer que no se sabe arreglar), si no el esmero y dedicación que le ponemos [NOTA: ortografía y sintaxis del alumno].

Al señalar que pasar al baño a maquillarse es indispensable, que no es "malo" y, por el contrario, una mujer fea es la que "no se sabe arreglar", Beatriz proyecta una clara identificación ideológica con discursos sexistas que en general son cuestionados y rechazados en el medio académico, e incluso en los discursos públicos más amplios. Sin embargo, para Beatriz la crítica intelectual al sexismo y los estereotipos de género, parece no inmutarle. Por el contrario, no solo justifica la necesidad primordial que tienen las mujeres de cuidar su apariencia ("nuestra primera carta de presentación"), sino también el consumismo que esta ideología conlleva:

es bien sabido que las mujeres somos las consumistas numero uno y claramente morimos por el ultimo labial de la marca MAC aunque no tengamos para nuestro lunch en el comedor de la Universidad... Un papel importante es la auto aceptación, la mayoría no nos sentimos igual de seguras si estamos de cara lavada frente a las amistades y no porque nos consideremos horrendas, más bien es el hecho que con aunque sea un poquito de rímel lucimos mejor, y al saber que lucimos mejor proyectamos más seguridad... También consideran que es importante si el labial es de marca o no y les preguntamos si si era así ¿por qué? Contestaron que es más bien un nivel de status social no es lo mismo traer un labial de marca reconocida que lo anuncia la misma Rihanna, con destellos extraídos de Francia e importado a el que te encuentras en el tianguis que quien sabe si es nuevo

\subsection{Caso 2: Ideología futbolera masculina (dentro de la Matrix)}

En el contexto de los cursos de Cultura Contemporánea, suelo pedir a los alumnos que escriban una "autobiografía cultural", en la cual se enfoquen en una práctica cultural que haya sido muy significativa en sus vidas. Uno de los requisitos de la tarea es que, además de la narrativa personal, utilicen al menos 5 conceptos teóricos que ya hayan estudiado en clase, relacionados con la antropología y la sociología de la cultura (BOURDIEU, 1989; GARCÍA CANCLINI, 1990; GEERTZ, 1992; GIMÉNEZ, 2005 etc.). 
Esta actividad me ha sorprendido, pues un número importante de alumnos y alumnas desarrollan con todo detalle y mucha emotividad la gran "pasión" que tienen por el fútbol en general, y por equipos y jugadores específicos. El siguiente es un fragmento del texto escrito por Ernesto (pseudónimo), quien solo escribió una página:

Desde que tengo uso de razón el futbol ha sido para mí algo muy especial. Es mi deporte favorito, el único que juego, comento, veo, analizo, pienso, etc... Así me decreto un apasionado del futbol, y que por ningún motivo lo dejare de ver y practicar. Como lo mencione anteriormente, entre mas pasen los años, mas crecerá mi amor por el futbol.

En el escrito de Ernesto no se observa distancia entre el escritor y el mundo ideológico-cultural que describe. Él habla desde y a nombre del discurso, lo que aquí llamo "dentro de la Matrix". Se auto-construye como un sujeto enteramente sujetado al discurso del Otro (el fútbol), que él no ve como un Otro, sino como Sí mismo ("es lo que soy, en lo único que pienso, de lo único que hablo, lo que más amo...”). En términos de Bakhtin, lo asume como un discurso autoritativo que es a la vez internamente persuasivo. Por lo mismo, su ensayo en conjunto falló en utilizar analítica y críticamente los conceptos del curso, pues usarlos implicaba descentrarse y poner distancia para ver "desde fuera" la relación de un individuo con una práctica cultural manufacturada, promovida e inculcada por agentes sociales cuyo poder es manifiesto en el mundo actual (los medios masivos, los negociantes del fútbol etc.).

\subsection{Caso 3: Ideología futbolera femenina (dentro de la Matrix)}

El texto de Graciela es resultado de la misma clase que el de Ernesto (Cultura contemporánea). Se presenta solo como ejemplo de la creciente "afición" o "pasión" de las mujeres jóvenes mexicanas por el fútbol, lo que era inusual en las mujeres.

Hoy en día puedo presumir haber vivido muchas experiencias con mi equipo de fútbol, una de las mayores experiencias que he tenido fue cuando se enfrentaron América vs Pumas... esto ponía un dilema en mi vida pero la realidad es que ya en el juego disfrute cada acción ... todo empezó con un penal a favor del América y así se mantuvo hasta el minuto 34 cuando el árbitro cobró un penal a favor de Pumas, con esto el partido entró en un empate muy ríspido pero al minuto 82 una 
genialidad del ex jugador del América Vicente Matías Vuoso puso las cosas en su lugar y con esto el América se quedó con los tres puntos... Y es así cómo algo completamente ajeno a mi vida se convirtió en parte importantísima de ella, mi pasión por el América.

Al igual que el texto de Ernesto, en su autobiografía cultural Graciela también elige hablar sobre su "pasión” por el fútbol. Notablemente, ella establece una identificación total con "su" equipo, es decir, borra o anula toda posible distancia entre su identidad y la del discurso (cultura-ideología) que expone en el ensayo. Podría decirse que sujeto y estructura social se fusionan al plantear que un partido entre equipos totalmente ajenos a su vida personal, puede convertirse en un dilema en su vida: "una de las mayores experiencias que he tenido fue cuando se enfrentaron América vs Pumas, esto ponía un dilema en mi vida". Otro rasgo interesante es la apropiación que Graciela hace del vocabulario y de las frases arquetípicas del discurso mediático-futbolero ("el partido entró en un empate muy ríspido", "una genialidad del ex jugador Vicente Macías Vuoso puso las cosas en su lugar”). Se aprecia aquí, justo lo que Bakhtin denomina apropiación del lenguaje: tomar palabras de las bocas de otros para usarlas con nuestras propias intenciones y acentos; esto es posible por el lugar importantísimo que el equipo "América" tiene en la vida de Graciela. En suma, no se aprecia aquí ninguna distancia entre sujeto y objeto del discurso; es un discurso desde "dentro de la Matrix".

\subsection{Caso 4: Ideología televisiva (saliendo de la Matrix)}

Al igual que Ernesto y Graciela, Keila proviene de una familia de clase trabajadora e ideología tradicional-conservadora, muy orientada al consumo de símbolos y discursos culturales mediáticos. Sin embargo, a diferencia de ellos, en su autobiografía cultural (realizada en el curso de Cultura Contemporánea) Keila entrelaza descripción y comentarios reflexivos sobre su historia. Se trata de un intento consciente por tomar distancia reflexiva respecto a las prácticas culturales que ella misma reconoce como "de masas" y que descubre no como una elección, sino como lo único disponible en su infancia. Es probable que este texto sea el primero en su vida en el que Keila discute conscientemente su posicionamiento vis-a-vis las prácticas y los discursos que le inculcaron en su infancia. Su ensayo abre con una cita teórica a la que yuxtapone su relato autobiográfico: 
Es importante hacer referencia sobre lo que es cultura de acuerdo con Gilberto Giménez, (2009) “es la organización social del sentido, (saberes creencias, valores...) interiorizada por los individuos... implicando que no existe cultura sin sujeto ni sujeto sin cultura" (p. 195).

Nací el día 06 de noviembre de 1991, hija de padres trabajadores, de religión católica... Durante mi infancia me dedique únicamente a ver caricaturas y jugar, eran mis únicas ocupaciones y preocupaciones... Durante mi estancia en la primaria me fue difícil comenzar a relacionarme con los compañeros de salón, el poder participar en clase era un martirio y sin duda alguna lo sigue siendo, creo que eso fue a consecuencia de la maestra que me toco en primer año de primaria que me dejo traumada, los libros se comenzaron a convertir en mis enemigos nuca les entendía y me regañaban por no comprender las lecturas, poco a poco comencé a entender en que consistía la primaria y fui aplicándome, participaba en cuanto festival hacían, así durante los 6 años en la primara en donde también comencé a cambiar las caricaturas por las novelas las cuales nunca me las perdía, me sabia de memoria todas... Actualmente estoy en la universidad y aunque aun es pequeña mi estancia aquí, mis gustos y preferencias se han modificado, ahora tengo el interés por los libros, la incertidumbre por saber que hay en las bibliotecas y para que sirven, sinceramente nunca antes lo había echo a profundidad como ahora, estoy en un proceso en el cual estas cambiando mis gustos e ideologías sobre la vida, ahora ya no veo novelas ni programas domingueros, etc.

Superficialmente, el escrito de Karla exhibe una serie de errores formales (puntuación, acentuación, ortografía), lo que podría impulsar a un profesor a mirarlo como un ejemplo más de escritura problemática de alumnos pobremente alfabetizados. Pero visto con detenimiento, este escrito es muy interesante, pues da evidencia de un proceso evolutivo en la apropiación del discurso académico, y no solo eso, sino que evidencia también un proceso de crecimiento y de re-construcción personal. A diferencia de sus compañeros de los casos 1 a 3, Keila no solo se describe a sí misma como parte de un discurso, sino que historiza su experiencia de vida. Esta historización implica revisar los orígenes de su personalidad y de sus marcos de conocimiento en el presente, que ella ve como resultado de estar expuesta a la televisión comercial por años y asimilar-memorizar todo lo que consumía sin resistencia ni mediación interpretativa. La distancia aparece cuando se posiciona desde su presente como alumna universitaria que descubre con curiosidad y asombro otras perspectivas ("aunque aún es pequeña mi estancia aquí, mis gustos y preferencias se han modificado, ahora tengo interés por los libros, la incertidumbre por saber qué hay en las bibliotecas..."). Especialmente interesante en este 
ensayo es la articulación explícita de un proceso de cambio o desarrollo ideológico. En sus palabras, "estoy en un proceso en el cual están cambiando mis gustos e ideologías sobre la vida...”. Keila demuestra este proceso incluso a través de una gráfica que diseñó para su ensayo (Figura 1), y en la que pone en juego la distinción conceptual entre lo culto, lo popular y lo masivo (del antropólogo Néstor García Canclini), que ha sido estudiada en clase, para analizar su proceso de cambio ideológico.

FIGURA 1 - Gráfica elaborada por Keila

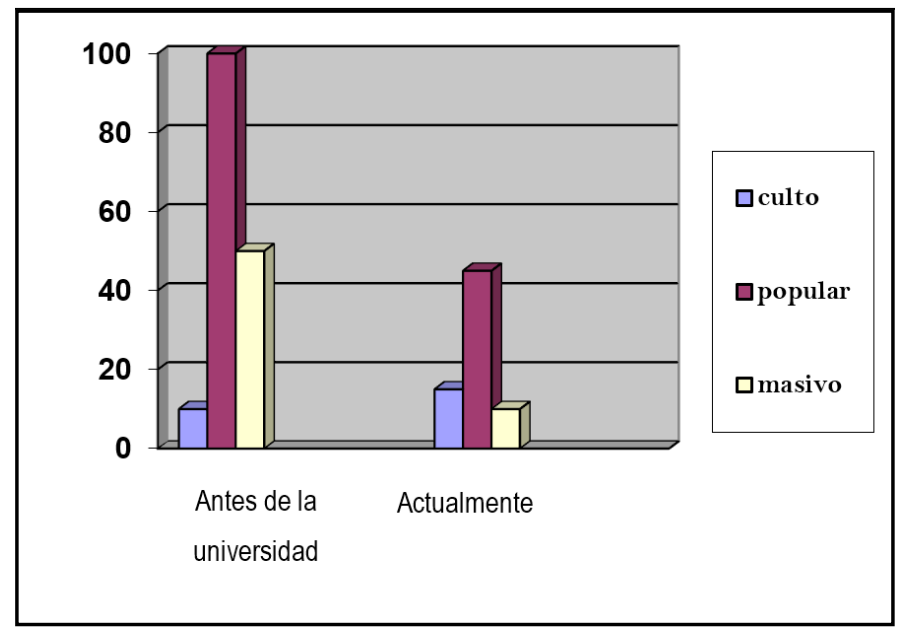

\subsection{Caso 5: Ideología crítica emergente (fuera de la Matrix)}

$\mathrm{Al}$ igual que sus compañeros de los casos 1-4, Lisset es también de origen socioeconómico bajo, pero su caso permite añadir una dimensión más en el análisis: la personalidad. A diferencia de los alumnos anteriores, Lisset es más despierta, activa y participativa en clase. Sus ojos reflejan una viva curiosidad, que expresa con mayor espontaneidad al tomar la palabra en clase. Aun cuando sus escritos reflejan una historia de vida parecida a la de sus compañeros, de condiciones de vida precarias y con acceso muy limitado a espacios y prácticas culturales diversas, Lisset es aún más proactiva que Keila en su ensayo. Busca no solo reflexionar sobre su narrativa, sino que utiliza literatura crítica (que no estudiamos en clase) para acompañar y enmarcar su relato (por ejemplo, una cita de Paulo Freire). Así mismo, emplea subtítulos que explicitan una intención analítico-crítica: "¿Para qué estudiamos?", "El mito", "Escuela o fábrica", "Otro enfoque”. 


\section{¿PARA QUÉ ESTUDIAMOS?}

Lo recuerdo como si hubiera sido ayer. No conseguí dormir en toda la noche. Cuando mire el reloj eran las $4 \mathrm{am}$. Cansada de la cama decidí levantarme y tomar una taza de café para calmar mis nervios. Comencé a dar vueltas en la pequeña sala de mi casa esperando que el reloj avanzara más rápido. Después de cinco tazas de café mire nuevamente el reloj y me di cuenta de que había llegado la hora. Era el momento de la verdad. Por fin sabría si seria uno de los 17 de cada 100 mexicanos que ingresan a la Universidad. Respire profundo y comencé a teclear la pagina donde se publicarían los resultados. Cuando localice mi número de folio el miedo se apodero de mí. Cerré mis ojos con fuerza para no mirar el que imaginaba seria un resultado negativo, pero respire profundo y mire fijamente el monitor. No podía creerlo había sido aceptada. Una inmensa felicidad me invadió por completo incluso debo admitir que derrame algunas lagrimas. Sin embargo ahora que estoy a punto de terminar el primer trimestre de la carrera de Administración a toda esa felicidad se le sumo una gran duda ¿Para que estoy estudiando? Si es que realmente lo estoy haciendo.

Escuela o Fábrica

"Estudiar no es un acto de consumir ideas sino de crearlas y recrearlas" (Paulo Freire)

En la Universidad se utiliza un sistema educativo llamado constructivista, significa que el alumno debe de tomar iniciativa y no solo consumir ideas debe de argumentarlas y/o aportarlas, es difícil e incluso ilógico llevarlo a la práctica cuando en la primaria, secundaria y preparatoria no nos enseñan a hacerlo tan solo nos convierten en consumistas de información.

Las escuelas matan nuestra creatividad desde pequeños, virtud con la cual nacemos, lo hacen desde el momento que a sus niños los limitan, callan, exigen solo obediencia, dictan, castigan, amenazan... Todo esto y más hacen que la escuela se perciba como una cárcel perdiendo el interés por el conocimiento. Es difícil pretender que de un momento a otro surja la creatividad que poco a poco fue desapareciendo durante nuestra vida escolar.

Pero hay algunas cosas que no dejan de enseñarnos incluso en la universidad. Una de ellas es competir. Constantemente los maestros fomentan la competencia dando algún incentivo a quien termine primero, quien lo haga mejor, quien haga más... Cuando deberían fomentar valores como la paz, cooperación, libertad, solidaridad, felicidad etc. 
La diferencia entre el ensayo de Lisset y el de Keila es de grado. Lisset utiliza con mayor claridad y frecuencia literatura e ideas críticas, tomadas de autores críticos (como Paulo Freire o Ken Robinson) y la introduce, pero no como "exposición del tema", sino las entrelaza con su propio discurso. Por ejemplo, cuando escribe: "Las escuelas matan nuestra creatividad desde pequeños, virtud con la cual nacemos, lo hacen desde el momento que a sus niños los limitan, callan, exigen solo obediencia, dictan, castigan, amenazan...", la frase "las escuelas matan la creatividad" es una frase de Ken Robinson, tomada de un video TED que vimos y comentamos en clase. Lisset no se molesta en exponer, citar y referenciar dicho video, sino que directamente usa las palabras e ideas que le permiten decir lo que quiere decir, en este caso que efectivamente, según su propia experiencia, los alumnos terminan silenciados y sumisos en escuelas que matan la creatividad.

\subsection{Caso 6: Ideología crítica avanzada (fuera de la Matrix)}

Finalmente, veamos el caso de Adelina, alumna cuyo posicionamiento tanto en las conversaciones de clase como en sus escritos es claramente "fuera de la Matrix". Precisamente porque un sujeto que toma distancia reflexiva y crítica ante la estructura social y sus discursos dominantes, es un hablante/escritor que tiene mucho qué decir, el discurso de Adelina es más fluido que los de Keila y Lisset. Transcribo un pasaje extenso para apreciar estos rasgos:

"De cincuenta mil doscientos cincuenta y seis jóvenes que presentaron el examen de ingreso para estudiar una carrera en la Universidad Autónoma Metropolitana (UAM), solamente seis mil novecientos setenta y cinco fueron aceptados" (Hernández, 2012)

Entrar a la universidad es hoy uno de los sueños frustrados de millones de jóvenes. Culpables hay muchos, por ejemplo tenemos la mafia educativa llamada SNTE encabezada por Elba Esther Gordillo, también la complicidad gobierno-mafia educativa que genera nuestras paupérrimas políticas educativas donde sobran hummers, lap tops, remuneraciones a fin de año pero se limosnea la calidad educativa, se recortan los contenidos en los programas educativos y se festeja la mediocridad. A pesar de esto siguen existiendo jóvenes ingenuos que siguen creyendo en el sistema educativo y deciden postularse para ingresar a la universidad. Bastante han mostrado las estadísticas sobre aquellos que no lograron ingresar, ya se han movilizado las masas en pro de la ampliación de la 
matrícula, pero aún no escuchamos a los "privilegiados" decirnos lo que es realmente la Universidad.

Es momento de que la voz de los que viven en carne propia la realidad detrás de las estadísticas sobre la deserción, la falta de presupuesto, los malos maestros y todas aquellas peculiaridades de la que está conformada la universidad digan lo que es ser un estudiante universitario y lo que es para ellos la universidad.

Adelina señala explícitamente factores y agentes sociales que influyen en crear y mantener un estatus quo de privilegios y exclusiones socioeconómicas y educativas (refiere, por ejemplo, a los líderes del sindicato magisterial). No habla, por tanto, solo desde la particularidad de su experiencia personal (que tampoco omite), sino que hace afirmaciones y reflexiones sobre procesos y agentes sociales más amplios. Es decir, visualiza los problemas como productos de un sistema social: "se limosnea la calidad educativa, se recortan los contenidos en los programas educativos y se festeja la mediocridad". Reconoce y quizás denuncia, en este contexto, la ingenuidad de los jóvenes "que siguen creyendo en el sistema educativo y se postulan para ingresar a la universidad". Finalmente, un rasgo cualitativamente distintivo entre el ensayo de Adelina y el resto de los casos expuestos, es que ella no solo expresa una descripción, narración o reflexión de manera directa, sino que anticipa y decide una estrategia retórico-argumentativa y la realiza en una estructura u organización textual que es visible en el conjunto del texto (1. Los privilegiados, 2. Los antagonistas, 3. La médula espinal). Esta capacidad retórica se expresa también en el uso de meta-lenguaje para informar al lector cuál es dicha estrategia, la cual incluye nociones discursivas tales como perspectiva (desde la perspectiva del universitario), fuentes de información (datos estadísticos y estudios), método de abordaje (comparar la realidad y la ficción), y agentes sociales (alumnos, profesores y modelos educativos):

Así este ensayo pretende mostrar a la universidad como es desde la perspectiva del universitario, los datos estadísticos y los estudios contra la experiencia; comparando la realidad y la ficción para dar un panorama más amplio a todos aquellos cuyo sueño de entrar a la universitaria aún se muestra como un milagro en espera. Para ello encuentro necesario hablar sobre los alumnos (parte sustancial), los profesores y finalmente los modelos educativos (el caso concreto de la UAM-C). Todos estos elementos conforman lo que hoy me atrevo a llamar "El milagro universitario". 
Adelina se posiciona como sujeto social colectivo (estudiantes) vis a vis otros agentes sociales dominantes ("mafia educativa llamada SNTE", "gobierno-mafia" etc.). Así mismo, plantea una crítica explícita a la institución universitaria desde una identidad definida ("Es momento de que la voz de los que viven en carne propia la realidad detrás de las estadísticas... digan lo que es ser estudiante universitario"), y adopta para ello, una perspectiva o punto de vista explícitamente definidos ("este ensayo pretende mostrar a la universidad como es, desde la perspectiva del universitario"). En cuanto a rasgos formales, Adelina no solo escribe con corrección ortográfica y gramatical, sino que exhibe una "madurez" en el lenguaje, visible en el uso correcto y fluido de convenciones gramaticales y textuales, pero también en la selección de un vocabulario más afinado, agudo y preciso.

\section{Análisis y conclusiones}

Escritos como los anteriores, de varias generaciones de estudiantes universitarios, hacen evidente la gran diferencia entre quienes ven el mundo desde "dentro de la Matrix" y quienes lo ven desde "fuera de la Matrix". Matrix (1999) es una película de ciencia ficción, que retrata un futuro distópico en el que la "realidad" no es ya sino una realidad virtual o simulada llamada "la Matrix", creada por máquinas para someter a la población y convertir sus cuerpos en fuente de energía. En el mundo de la Matrix la gente cree que lleva una vida normal (ir al trabajo, hacer fiestas, pagar impuestos etc.); en realidad todos son esclavos que pasan su vida entera presos en incubadoras, desnudos y en posición fetal. Cada uno yace en un recipiente que contiene líquido y cables conectados a su espina dorsal, por los que se le "alimenta" no solo física, sino mentalmente. Neo, el protagonista de la historia, intuye que hay algo raro en el mundo y sus indagaciones lo llevan ante el misterioso Morpheus, quien le ofrece la disyuntiva de elegir entre seguir su vida ordinaria (soñando que es un hombre que va todos los días al trabajo, en una ciudad normal etc.) o unirse a los rebeldes e "ir hasta el fondo", donde verá con sus propios ojos qué es la Matrix.

"Matrix" es, por tanto, a la vez una metáfora visual de la matriz o útero femenino (que envuelve, aloja y alimenta al bebé durante la gestación, pero le impide contacto directo con el mundo), y un mundo de ideas "inyectadas", que Morpheus explica así ante Neo: "la Matrix es el mundo que ha sido puesto ante tus ojos para cegarte de la verdad: que eres un esclavo dentro de una prisión mental". 
Lejos de ser un simple relato de ficción, la película Matrix es un nodo de resonancias intertextuales, que a través de formas fílmicas contemporáneas reitera símbolos, narrativas y debates filosóficos, epistemológicos y políticos ancestrales. Entre otros, es evidente la alusión al mito de la caverna, de Platón, y a casi toda la literatura distópica, como Un mundo feliz (Huxley), (Orwell), Fahrenheit 451 (Bradbury), y otros. Todas estas obras giran alrededor de una idea común: la dificultad de distinguir entre sueños y realidad; la definición misma de "realidad"; el creciente control y el sometimiento social por medio de dispositivos tecnológicos e ideológicos; y la dificultad de los individuos para tomar conciencia, "despertar" y desafiar al sistema. Esencialmente, los relatos distópicos son historias que retratan una humanidad dominada por poderes que, mediante dispositivos tecnológicos, políticos, mediáticos, institucionales, son capaces de inculcar sueños, ilusiones, deseos, ideologías $\mathrm{y}$ creencias que fundamentalmente imponen un deber ser (identidad).

Más allá de la increíble semejanza entre los mundos distópicos de la literatura y el cine, y el mundo "real" que actualmente vivimos, lo cierto es que la escritura de los estudiantes universitarios no solo adolece de errores mecánicos (ortografía, sintaxis) o de problemas de contenido (imprecisiones conceptuales, incomprensión de teorías etc.), sino que en un nivel más global, su escritura refleja una visión acrítica del mundo, es decir, una visión "desde dentro de la Matrix". Desde ésta, cada tema es objeto simplemente de descripción y apreciación afectiva (me gusta, lo disfruto, lo sufro etc.), pero no es objeto de análisis crítico. Es decir, hablan desde una posición de inmersión dentro de ese mundo y simplemente les es imposible verlo "desde fuera" o a distancia. Lo ven, por tanto, como natural, y no encuentran motivos para desconfiar o distanciarse de esa "naturalidad". Los segundos, en cambio, toman distancia para describir y comentar lo que describen, de manera que ese mundo no les parece natural, sino creado, construido y diseñado por agentes específicos con fines específicos. Para poderlo analizar y develar, son estos estudiantes quienes se apropian realmente de los conceptos y de las teorías académicas, y los ponen en juego en su discurso escrito.

Como señalamos al inicio de este artículo, la investigación sobre el lenguaje y la literacidad en educación se ha movido desde un cognitivismo y lingüicismo hacia un enfoque sociocultural y dialógico que pone atención al carácter social, cultural e ideológicamente situados de todo acto de lenguaje (lectura, escritura, oralidad) y, por tanto, a los conflictos de identidad ideológica-cultural que enfrentan los sujetos para interpretar y apropiarse 
de los discursos académicos. Sin embargo, aún son pocos los autores que ponen al centro el análisis de las mediaciones ideológicas en la lectura y escritura críticas, aun cuando la falta de un pensamiento crítico es quizás la mayor queja del sistema educativo frente al discurso oral y escrito de los estudiantes. Especialmente en el mundo hispanohablante, son pocos los autores que abordan esta línea, que consideramos crucial para entender muchas cosas sobre la apropiación o la no apropiación del lenguaje y el discurso académico por parte de los estudiantes. Entre quienes han identificado y abordado directa y acertadamente esta cuestión, está Daniel Cassany y su grupo de investigación en la Universitat Pompeu Fabra de Barcelona $(2003,2015,2017)$, quienes han señalado la necesidad de estudiar "cómo se lee y se escribe la ideología o, dicho de otro modo, el punto de vista, el sesgo, la mirada o la subjetividad inevitable que esconde cualquier texto" (CASSANY, 2015, p. 91).

En este sentido, y a reserva de profundizar en el análisis del corpus extenso de este proyecto, hasta ahora he observado que la escritura problemática (en aspectos de superficie, como la acentuación, puntuación, sintaxis, vocabulario etc.) es consistente con el posicionamiento ideológico. Es decir, en general los mejores escritos en cuanto a corrección, estilo, coherencia, organización, y convenciones de citación/referenciación suelen ser de quienes hablan desde "fuera de la Matrix". Y viceversa, los escritos más cargados de errores de todo tipo suelen ser de alumnos que hablan desde "dentro de la Matrix". Develar las conexiones con más precisión requiere aun estudio metódico; por ahora solo señalo que este es un patrón que surge en mis datos.

Por otro lado, los casos mostrados reflejan que más que una dicotomía "dentro" vs "fuera" de la Matrix sería conveniente desarrollar un continuo de desarrollo ideológico (en términos Bakhtinianos), que por ahora caracterizo como una distancia mayor o menor entre el sujeto y los discursos hegemónicos, y entre el sujeto y su propio discurso. Provisoriamente distingo cuatro niveles en este continuo y los caracterizo así:

Distancia 0. El sujeto no se distingue a sí mismo del discurso que enuncia. Podría decirse, siguiendo a Foucault $(1988,1994)$, que en estos casos el discurso hegemónico habla a través del sujeto. En este caso, los conceptos teóricos requeridos por la tarea de escritura son reducidos a palabras despojadas de su sentido conceptual y empleadas solo en un sentido gramatical, es decir como sustantivos, verbos o adjetivos para 
"rellenar" oraciones sin ninguna implicación analítica o crítica. (Casos prototípicos: Beatriz, Ernesto)

Distancia 1. El sujeto intenta usar los conceptos con fines analíticos, pero su ejercicio es incipiente, al parecer por una limitada comprensión y asimilación de los mismos. La intención, sin embargo, no es distanciarse del discurso autoritativo para examinarlo o cuestionarlo, sino "cumplir con la tarea" usando conceptos que el sujeto no tiene intención de adoptar como parte de sus esquemas ideológicos y cognitivos.

Distancia 2. El sujeto comienza a usar algunos conceptos con fines analíticos y críticos. La diferencia central con la distancia 1 es que aquí sí hay intención de adoptar los conceptos y una mirada crítica como parte de los esquemas ideológicos y cognitivos propios. (Caso prototípico: Keila)

Distancia 3. El sujeto toma distancia de los discursos hegemónicos y los somete a escrutinio y/o crítica con base en conceptos, teorías, autores o datos intencionalmente elegidos para revelar las inconsistencias, las fallas, o las falsedades del discurso autoritativo. En estos casos, la escritura es más clara y organizada en todos los sentidos: la organización superficial del texto, la sintaxis y la coherencia de los párrafos y, sobre todo, la lógica argumentativa que expresa una postura y una voz personal definida. (Caso prototípico: Adelina; Caso transicional: Lisset).

Finalmente, planteo algunas preguntas clave en relación con la literacidad académica: ¿Por qué importa que los alumnos escriban "académicamente" y qué significa realmente ser una persona académicamente letrada? Del análisis realizado en este artículo surgen varias respuestas que pueden abonar a continuar con esta línea de indagación. La primera sería que, efectivamente, un egresado universitario debería tener un manejo más "avanzado" del lenguaje escrito, en el sentido de utilizar las convenciones ortográficas, gramaticales y estilísticas propias de una persona con educación "superior". Pero eso no basta. Es necesario pensar y "hablar" (escribir) con el lenguaje de las disciplinas. De nada sirve que alguien escriba sin faltas de ortografía, si a la hora de identificar y plantear problemas y soluciones no logra "ver" y pensar desde la perspectiva de un ingeniero, abogado, sociólogo, antropólogo etc. El lenguaje de las disciplinas no es simplemente una lista de términos para decir "lo mismo" de modo rebuscado; es esencialmente un cuerpo de conceptos que nos habilita a ver y pensar el mundo de una manera 
distinta y más precisa, al menos desde el punto de vista de las respectivas teorías. Y aquí observamos una gran limitación de muchos estudiantes y egresados universitarios: cuando hablan o escriben tienden a hacerlo como si no hubieran "pasado por la universidad", con un vocabulario e ideas que bien podrían ser de cualquier persona que no hizo una carrera universitaria. Aun así, tampoco es suficiente apropiarse del lenguaje "técnico" de las disciplinas. No se trata solo de enseñar a escribir académicamente, sino que los estudiantes se apropien de un discurso y prácticas que a la vez son lingüísticas, retóricas, cognitivas e ideológico-culturales. El fin último no es desarrollar una "competencia comunicativa" (ese es un medio, no un fin), sino desarrollar una conciencia social informada, crítica y reflexiva, propia de ciudadanos, profesionistas y seres humanos libres, capaces y críticos. La escritura en general y la escritura académica en particular no son fines, sino medios para convertirse en sujetos pensantes, creativos y activos, que no simplemente encajen en una sociedad cada vez más alienante, injusta y ecocida, sino que puedan mirarla y mirarse "desde fuera", de manera que no solo la reproduzcan, sino la cuestionen y desafien, y eso exige mirar desde "fuera de la Matrix".

\section{Referencias}

BAKHTIN, M. The dialogic imagination: four essays. Austin: University of Texas Press, 1981.

BALL, A.; FREEDMAN, S. (Ed.). Bakbtinian perspectives on language, literacy, and learning. Cambridge: Cambridge University Press, 2004. Doi: https://doi. org/10.1017/CBO9780511755002

BARTHOLOMAE, D. Inventing the university. In: ROSE, M. (Ed.). When a writer can't write: studies in writer's block and other composing-process problems. New York: Guilford, 1985.

BARTON, D. Literacy: an introduction to the ecology of written language. Oxford: Blackwell, 1994.

BARTON, D.; HAMILTON, M.; IVANIC, R. (Ed.). Situated literacies: reading and writing in context. London: Routledge, 2000.

BOURDIEU, P. Sociologia y cultura. Ciudad de México: CNCA, 1989.

BRUNER, J. El habla del niño. Barcelona: Paidós, 1986. 
CAMARGO, T. La Lengua Materna en la Lengua Extranjera: Un arma de doble filo. In: CARIELLO, G. et al. (Comp.). Tramosy Tramas VI: culturas, lenguas, literaturas e interdisciplina. Estudios comparativos. Rosario: Laborde Libros Editor, 2017.

CANAGARAJAH, A. S. Critical academic writing and multilingual students. Michigan: University of Michigan Press, 2002. Doi: https://doi.org/10.3998/mpub.8903

CASSANY, D. Aproximaciones a la lectura crítica: teoría, ejemplos y reflexiones. Tarbiya, Madrid, n. 32, p. 113-132, 2003. Disponível em: <https://goo.gl/ cWCK3w>. Acesso em: 9 jun. 2018.

CASSANY, D. Investigaciones y propuestas sobre literacidad actual: multiliteracidad, internet y criticidad. In: CONGRESO NACIONAL CÁTEDRA UNESCO PARA LA LECTURA Y LA ESCRITURA, 1., 24-26 ago. 2005, Concepción. Actas... Concepción: Universidad de Concepción, 2005. Disponível em: <https://goo.gl/ vAkH81>. Acesso em: 27 dez. 2017.

CASSANY, D. Literacidad crítica: leer y escribir la ideología. ResearchGate, Berlin, 2015. Disponível em: <https://goo.gl/Ry72eW>. Acesso em: 23 dez. 2017.

CAZDEN, C. Vygotsky, Hymes and Bakhtin: from word to utterance and voice. In: CAZDEN (Ed.). Whole language plus: essays on literacy in the United States and New Zeland. New York: Teachers College Press, 1992.

ERRAZURIZ, M. C. et al. Diagnóstico de la escritura de un ensayo de alumnos novatos de Pedagogía en el campus Villarica UC, Chile. Perfiles educativos, Ciudad de México, v. 37, n. 150, p. 76-90, 2015.

ESPINOZA, V. A. Empoderamiento a través de la escritura en la formación inicial de los docentes. 2016. Tese (Doutorado em área) - Instituto Superior de Ciencias de la Educación del Estado de México, Toluca, 2016.

FERREIRO, E.; TEBEROSKY, A. Los sistemas de escritura en el desarrollo del niño. Ciudad de México: Siglo XXI, 1979.

FOUCAULT, M. El sujeto y el poder. In: DREYFUS, H.; RABINISU, P. Michel Foucault: más allá del estructuralismo y la hermenéutica. Ciudad de México: Unam, 1988. Doi: https://doi.org/10.2307/3540551

FOUCAULT, M. El orden del discurso. Barcelona: Tusquets, 1994.

FREEDMAN, S. W.; BALL, A. Ideological becoming: bakhtinian concepts to guide the study of language, literacy, and learning. In: BALL, A.; FREEDMAN, S. (Ed.). Bakbtinian perspectives on language, literacy, and learning. Cambridge UK: Cambridge University Press, 2004. Doi: https://doi.org/10.1017/CBO9780511755002.001 
GARCÍA CANCLINI, N. Culturas híbridas: estrategias para entrar y salir de la modernidad. Ciudad de México: CNCA-Grijalbo, 1990.

GEE, J. P. What is literacy? In: MITCHELL, C.; WEILER, K. (Ed.). Rewriting literacy: culture and the discourse of the other. New York: Bergin \& Garvey, 1991. GEE, J. P. Social linguistics and literacies: ideology in discourses. London: Taylor \& Francis, 1996.

GEE, J. P. Learning language as a matter of learning social languages within discourses. In: HAWKINS, M. (Ed.). Language learning and teacher education: a social approach. Bristol: Multilingual Matters, 2004.

GEERTZ, C. La interpretación de las culturas. Barcelona: Gedisa, 1992.

GIMÉNEZ, G. Teoría y análisis de la cultura. Ciudad de México: Conaculta, 2005.

GONZÁLEZ, R. O. (Coord.). Habilidades lingüísticas de los estudiantes de primer ingreso a las instituciones de educación superior del área metropolitana de la ciudad de México. Ciudad de México: Anuies, 2015.

GOODY, J.; WATT, I. The consequences of literacy. In: GOODY, J. (Ed.). Literacy in traditional societies. Cambridge: Cambridge University Press, 1968.

HAYES, J.; FLOWER, L. Identifying the organization of writing processes. In: GREGG, L; STEINBERG, E. Cognitive processes in writing. Hillsdale: Lawrence Erlbaum, 1980.

HEATH, S. B. Ways with words: language, life, and work in communities and classrooms. Cambridge: Cambridge University Press, 1983.

HENAO, J. I. et al. Niveles de literacidad de los estudiantes de Psicología de la Institución Universitaria de Envigado. Zona Próxima, Barranquilla, n. 15, p. 54-77, 2011.

HERNÁNDEZ-ZAMORA, G. Escritura académica y formación de maestros: ¿Por qué no acaban la tesis? Tiempo de Educar, Toluca, v. 10, n. 19, p. 11-40, 2009.

HERNANDEZ-ZAMORA, G. Academicism in language: "A Shelob's web that devours and kills from inside". In: RIVERS, D.; ZOTZMANN, K. (Ed.). Isms in language education: oppression, intersectionality and emancipation. Berlin: De Gruyter Mouton, 2017. Doi: https://doi.org/10.1515/9781501503085-009

HULL, G.; HERNÁNDEZ-ZAMORA, G. Literacy. In: HULT, F.; SPOLSKY, B. (Ed.). The handbook of educational linguistics. Oxford: Blackwell, 2008. Doi: https:// doi.org/10.1002/9780470694138.ch23 
IVANIC, R. Writing and Identity: the discoursal construction of identity in academic writing. Amsterdam: John Benjamins Publishing, 1998. Doi: https://doi. org/10.1075/swll.5

LAVE, J.; WENGER, E. Situated learning: legitimate peripheral participation. Cambridge: Cambridge University Press, 1991. Doi: https://doi.org/10.1017/ CBO9780511815355

MATRIX. Direção: Lilly Wachowski e Lana Wachowski. Burbank: Warner Home Video 1999.

OLSON, D. R. From utterance to text: the bias of language in speech and writing. Harvard Educational Review, Cambridge, v. 47, n. 3, p. 257-281, 1977. Doi: https:// doi.org/10.17763/haer.47.3.8840364413869005

ONG, W. Orality and literacy: the technologizing of the word. New York: Routledge, 1982. Doi: https://doi.org/10.4324/9780203328064

SCRIBNER, S.; COLE, M. The psychology of literacy. Cambridge: Harvard University Press, 1981. Doi: https://doi.org/10.4159/harvard.9780674433014

STREET, B. Literacy in theory and practice. Cambridge: Cambridge University Press, 1984.

VYGOTSKY, L. S. Mind in society: the development of higher psychological processes. Cambridge: Harvard University Press, 1978.

Data de submissão: 31/12/2017. Data de aprovação: 07/06/2018. 